\title{
The study and comparative analysis of GerdQ and GSRS Questionnaires on gastroesophageal reflux disease diagnostics
}

\author{
Serhii Zaika, Iryna Paliy, Viacheslav Chernobrovyi, Oleh Oleksandrovych Ksenchyn \\ National Pirogov Memorial Medical University, Vinnytsya, Ukraine
}

Gastroenterology Rev 2020; 15 (4): 323-329

DOI: https://doi.org/10.5114/pg.2020.101561

Key words: gastroesophageal reflux disease, questionnaires, intraluminal oesophageal impedance-pH monitoring.

Address for correspondence: Oleh Oleksandrovych Ksenchyn, Department of Internal and Family Medicine, National Pirogov Memorial Medical University, Pirogova 56, 21018 Vinnytsia, Ukraine, e-mail: vinshura@gmail.com

\begin{abstract}
Introduction: Clinical questionnaires have some limitations compared to instrumental diagnosis of gastroesophageal reflux disease (GERD), but clinical diagnosis of GERD based on typical symptoms is pragmatic and well-established by societal guidelines.

Aim: To study the diagnostic value and provide comparative analysis of GerdQ and GSRS questionnaires regarding the GERD diagnostics based on a comparison of the questionnaires with the results of intraluminal oesophageal impedance-pH monitoring in Ukraine.

Material and methods: Twenty-eight patients (11 men and 17 women with a mean age of $47 \pm 2.4$ years and a mean body mass index of $25.6 \pm 1.1 \mathrm{~kg}$ ) filled in the GerdQ and GSRS questionnaires and underwent 24-hour multichannel intraluminal oesophageal impedance-pH monitoring.

Results: The GerdQ questionnaire showed a significantly strong correlation between the total score of the questionnaire and the key indicators of 24-hour impedance-pH monitoring: AET $\left(r_{s}=0.793\right)$, acid reflux episodes $\left(r_{s}=0.796\right)$, and liquid reflux episodes $\left(r_{s}=0.730\right)$. Correlation of reflux syndrome according to the GSRS questionnaire was established between the acid reflux episodes $\left(r_{s}=0.530\right)$, the episodes of all fluid refluxes $\left(r_{s}=0.598\right)$, and AET $\left(r_{s}=0.560\right)$, but the strength of the correlation relationships is weaker. The GerdQ questionnaire showed a sensitivity of $78.6 \%$, specificity of $92.9 \%$, and accuracy (diagnostic efficiency) of $85.7 \%$.

Conclusions: The use of the GerdQ questionnaire for the diagnosis of GERD is optimal in everyday practice for deciding whether to prescribe "ex juvantibus" therapy or whether to use instrumental examination methods (upper endoscopy, oesophageal pH monitoring, oesophageal impedance-pH monitoring).
\end{abstract}

\section{Introduction}

Increasing attention is being been paid by doctors and researchers to gastroesophageal reflux disease (GERD). A large number of practical recommendations and guidelines for the diagnosis and treatment of GERD have been published in various countries [1-4].

The standard for the diagnosis of this disease is upper endoscopy and oesophageal pH monitoring [5], and oesophageal impedance-pH monitoring, as the most sensitive method of research because this allows the identification of not only acidic but also weakly acidic and gas refluxes, which also play a role in the onset of GERD symptoms [6-8]. However, the above methods of diagnosis are expensive, invasive, and not well toler- ated by patients. This complicates their use in routine practice in the examination of patients with symptoms of GERD.

For standardisation of GERD definition, symptoms, diagnosis, and treatment approaches, the International GERD Consensus Group was created to develop a global definition and basic concepts for GERD. This group has been working for 2 years, and its results were outlined in the Montreal Consensus in 2006. The experts found it possible to establish a diagnosis of GERD and prescribe treatment without further examination, based on characteristic clinical symptoms (both oesophageal and non-oesophageal). The need for additional examination methods (upper endoscopy, $\mathrm{pH}$ - and impedance-pH 
monitoring) is determined by the physician, depending on the severity of the complaints and the presence of alarm symptoms [9].

A similar algorithm for the diagnosis of GERD is presented in the three-level reflux treatment guidelines (2008). At the first level (the self-care level), an available treatment option for GERD patients is self-administration of drugs for heartburn. If heartburn and regurgitation occur more than two times a week, patients are advised to contact their family doctor or therapist. In the presence of atypical symptoms, alarm symptoms, or ineffective treatment, the patient is directed to the third level, the gastroenterologist, who considers the feasibility of additional methods of examination and optimisation of treatment [10].

However, such an approach is fraught with difficulties associated with the subjective assessment of complaints by both the patient and the doctor. This is because in routine practice, there are patients with significant changes of the mucous membrane of the oesophagus but with unexpressed symptoms, or the patient is unaware of the possible complications and does not pay due attention to their symptoms [11, 12]. Conversely, sometimes a physician relying only on symptoms may misinterpret the severity of the disease and make diagnostic errors $[11,13]$. This is facilitated by the combination of classical GERD symptoms with gastric dyspepsia symptoms, irritable bowel syndrome, and a weak correlation between endoscopic results and severity of symptoms.

All of the above require the development of an accurate and objective diagnostic technique that would be non-invasive and possible for use in everyday practice by both gastroenterologists and primary care physicians (GPS and therapists). The most appropriate variant of such a technique is questionnaires. It should be noted that such questionnaires should be sensitive and specific on one hand and short and easy to fill on the other, so as not to cause problems for the patient when filling them out.

A large number of questionnaires for the diagnosis of GERD have been developed, but most of them are used for scientific research. Among those that can be widely used and are currently used in practice are: GSRS (Gastrointestinal Symptom Rating Scale), GSFQ (Gastrointestinal Short Form Questionnaire) [14], CDQ (Carlsson-Dent Questionnaire), and GerdQ. In order to ensure the use of questionnaire data, they must be translated and validated.

Thus, in the Lyon Consensus 2018, clinical questionnaires for the diagnosis of GERD are considered based on the assessment of the presence and frequency of typical manifestations such as heartburn and regurgitation. While these instruments have some limitations compared to instrumental diagnosis of GERD, clinical diagnosis and treatment of GERD based on typical symptoms are pragmatic and well-established public guidelines. Among these, CDQ and GerdQ questionnaires are recommended as having similar diagnostic value [15].

The following questionnaires were selected for our study:

- the GSRS (Gastrointestinal Symptom Rating Scale) is a classic questionnaire for patients with gastrointestinal disorders. As a result of a study in six countries, its usefulness for the evaluation of dyspeptic symptoms and reflux symptoms has been established; it has acceptable reliability and validity [16]. It consists of 15 questions grouped into five syndromes (clusters): abdominal, reflux, dyspeptic, diarrhoeal, and constipation. It is not specific for the diagnosis of GERD, but the presence of reflux syndrome allows its use;

- the GerdQ (Gastroesophageal Reflux Disease Questionnaire) was chosen by us as the most promising because it was created on the basis of three other statistically valid questionnaires for the evaluation of reflux syndrome (GIS, GSRS, RDQ) as a result of a largescale international DIAMOND study [17]. The purpose of this study was to create a questionnaire and prove its diagnostic value by comparing it with the results of instrumental examinations (upper endoscopy and $\mathrm{pH}$ monitoring). This questionnaire has shown its effectiveness in many studies [18-20]. In 2013 it was translated into Russian and validated for use [21].

As already mentioned, the data from the questionnaires were evaluated in comparison with the oesophageal $\mathrm{pH}$ monitoring data and/or upper endoscopy results [19, 20, 22-27], but not with the results of oesophageal impedance-pH monitoring, which allows the identification of weakly acidic and gas refluxes and is currently one of the best and most informative instrumental methods for the diagnosis of pathological gastroesophageal reflux.

\section{Aim}

The aim of the study was to study the diagnostic value and provide comparative analysis of GerdQ and GSRS questionnaires regarding the GERD diagnostics based on a comparison of the questionnaires with the results of intraluminal oesophageal impedance- $\mathrm{pH}$ monitoring in Ukraine.

\section{Material and methods}

Twenty-eight patients (11 men and 17 women with a mean age of $47 \pm 2.4$ years and a mean body mass index (BMI) $25.6 \pm 1.1 \mathrm{~kg}$ ) were enrolled in the study. All patients, after an explanation and after giving their informed consent, filled out the GerdQ and 
GSRS questionnaires, which included questions about their well-being during the last 7 days, after which the questionnaire scores were evaluated and calculated. While processing the GerdQ questionnaire, a total questionnaire score and a separate score on each of the six questions were noted: presence and frequency of heartburn, regurgitation, epigastric pain, nausea, heartburn at night, and frequency of medication intake. In the GSRS questionnaire all five syndromes were evaluated separately: abdominal, reflux, dyspeptic, diarrhoeal, and constipation.

According to the results of the GerdQ questionnaire, we identified 12 patients who had $\geq 8$ points, which is a criterion for GERD, and 16 patients who had $<8$ points, which was insufficient to establish a diagnosis of GERD in them.

All patients underwent 24-hour multichannel intraluminal oesophageal impedance-pH monitoring. We used a computer-based impedance-pH monitoring system, Acidogastrograph AG-3pH-4Z, developed by the medical-engineering staff of the Department of Internal and Family Medicine, National Pirogov Memorial Medical University, Vinnytsya, led by Prof. Viacheslav Chernobroviy. The microprobe electrode used in this study had a pH sensor and six impedance sensors (Figure 1). The microprobe was introduced transnasally, so that the $\mathrm{pH}$ sensor was located in the oesophagus $5 \mathrm{~cm}$ above the lower oesophageal sphincter (LOS), at the same time impedance sensors were formed by four segments of registration ( $3 \mathrm{~cm}, 5 \mathrm{~cm}, 7 \mathrm{~cm}$, and $12 \mathrm{~cm}$ above the LES).

The results of the 24-hour oesophageal impedance-pH monitoring were evaluated as follows:

- number of episodes of acid refluxes $(\mathrm{pH}<4)$;

- number of episodes of weakly acidic refluxes (pH 4-7);

- number of episodes of weakly alkaline refluxes $(\mathrm{pH}>7)$;

- number of episodes of gas refluxes;

- number of episodes of all liquid refluxes;

- number of episodes of all mixed reflux (gas - liquid);

- number of episodes of acid reflux lasting more than 5 min;

- total time with oesophageal $\mathrm{pH}<4$ (acid exposure time);

- total time with oesophageal $\mathrm{pH}>7$.

The results of the monitoring are presented in graphical and digital conclusions (Figure 2).

\section{Statistical analysis}

Statistica 7.0 (StatSoft Inc.) software was used for the statistical analysis. While assessing the study data, in addition to the descriptive statistical methods (mean, standard deviation, Student's t-test, Mann-Whit-

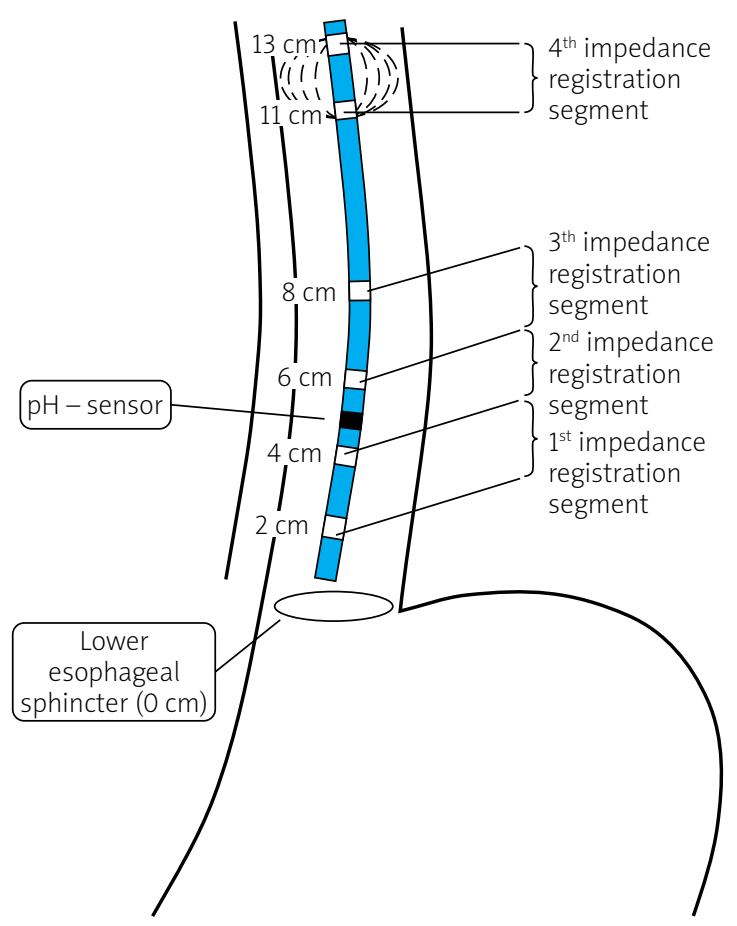

Figure 1. Schematic representation of microelectrode and the sensors on it

ney $U$ test, Spearman's Rank correlation coefficient). The sensitivity, specificity, and diagnostic accuracy of the method were calculated using the classical method of two-way contingency tables. The $p$-value $<0.05$ was considered significant.

\section{Results}

Relationship between the results of the GerdQ and GSRS questionnaires and the results of the 24-hour oesophageal impedance-pH monitoring

We evaluated the correlation between the results of the 24-hour oesophageal impedance-pH monitoring and the total score of the GerdQ questionnaire. According to the data obtained, a statistically significant strong positive correlation was established between the frequency of episodes of acid refluxes $(\mathrm{pH}$ <4) and the total points of the GerdQ questionnaire $\left(r_{s}=0.796\right)$, between the frequency of episodes of all fluid refluxes and the total points of the GerdQ questionnaire $\left(r_{s}=0.730\right)$, and between AET and the total score of the GerdQ questionnaire $\left(r_{s}=0.793\right)$. While assessing reflux syndrome according to the GSRS questionnaire, a statistically significant moderate correlation was established between the acid reflux episodes $(\mathrm{pH}<4)$ and the score of the reflux syndrome $\left(r_{s}=0.530\right)$, between the episodes of all fluid refluxes and the score of the reflux syndrome $\left(r_{s}=0,598\right)$, and between AET and the 


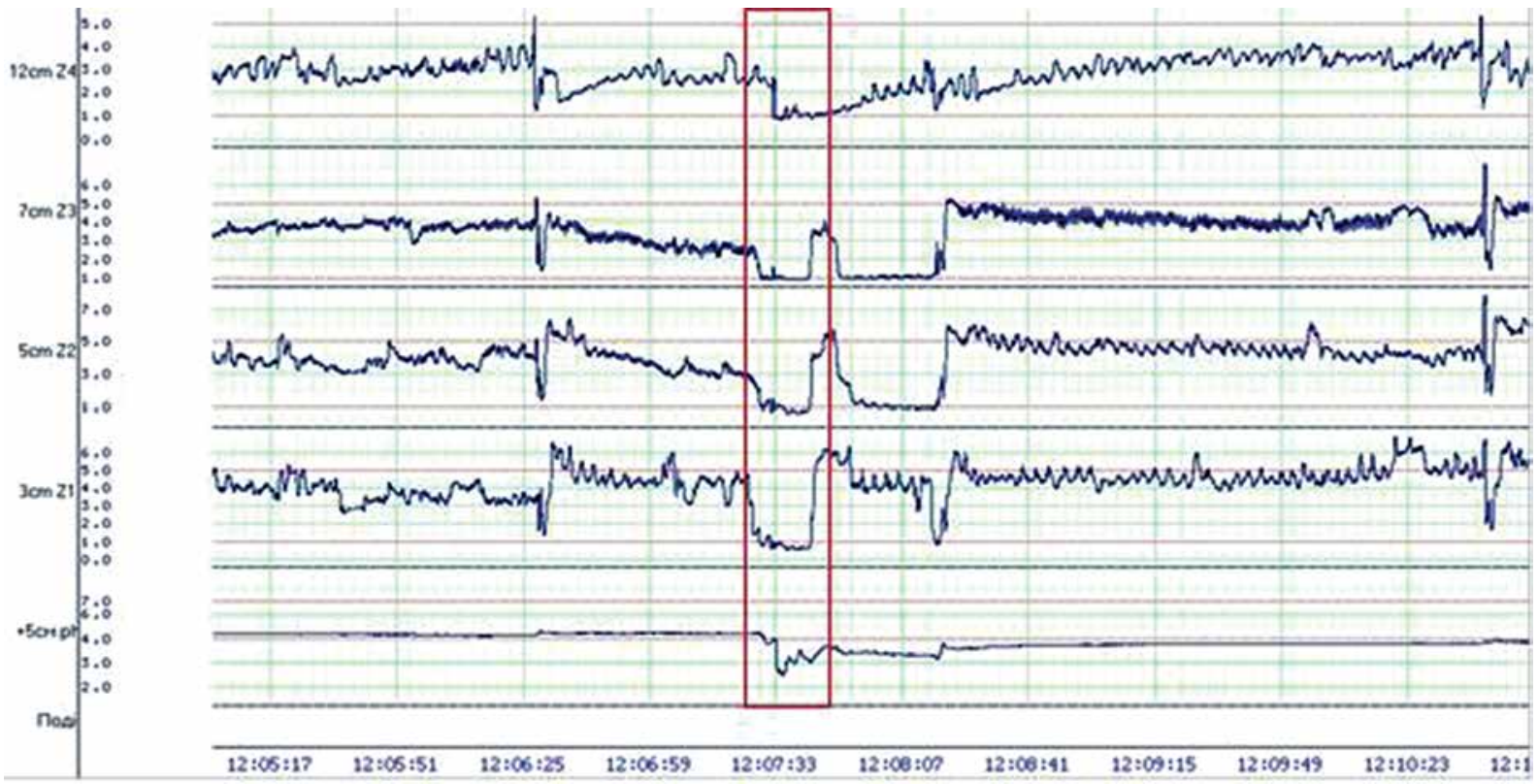

Figure 2. Part of the 24-hour oesophageal impedance-pH monitoring of patient $\mathrm{H}$ (with marked episode of acid gastroesophageal reflux)

reflux syndrome score $\left(r_{s}=0.560\right)$. The data are shown in Table I.

\section{GerdQ total score and 24-hour impedance-pH monitoring results}

As a result of the study, a statistically significant difference $(p<0.05)$ was established between the mean values of acid refluxes (55.38 \pm 6.12 in the GERD group

Table I. Correlation between the results of 24-hour oesophageal impedance-pH monitoring and the scores of GerdQ and GSRS questionnaires

\begin{tabular}{lcc}
$\begin{array}{l}\text { Indicators of 24-hour } \\
\text { impedance-pH monitoring }\end{array}$ & $\begin{array}{c}\text { Total scores } \\
\text { according to } \\
\text { GerdQ }\end{array}$ & $\begin{array}{c}\text { Scores } \\
\text { of reflux } \\
\text { syndrome } \\
\text { according to } \\
\text { GSRS }\end{array}$ \\
\hline Acid refluxes & $\mathbf{0 . 7 9 5 ^ { * }}$ & $\mathbf{0 . 5 3 0 ^ { * }}$ \\
\hline Weakly acid refluxes & 0.065 & 0.123 \\
\hline Weakly alkaline refluxes & 0.032 & 0.089 \\
\hline Gas refluxes & -0.162 & 0.008 \\
\hline Liquid refluxes & $\mathbf{0 . 7 3 0 *}$ & $\mathbf{0 . 5 9 *}$ \\
\hline Mixed refluxes (gas - liquid) & 0.106 & 0.127 \\
\hline Acid refluxes, lasting > 5 min & 0.375 & 0.163 \\
\hline Acid exposure time (AET) & $\mathbf{0 . 7 9 3 ^ { * }}$ & $\mathbf{0 . 5 6 * *}$ \\
\hline Time with pH > 7 & -0.306 & -0.194 \\
* & &
\end{tabular}

according to the GerdQ questionnaire vs. $23.29 \pm 6.53$ in the almost healthy group, according to the GerdQ questionnaire), gas refluxes ( $1.46 \pm 0.43$ vs. $3.46 \pm 0.86$, respectively), total fluid refluxes (71.15 \pm 8.37 vs. 33.8 \pm 5.97 , respectively), AET (12.42 \pm 3.65 vs. $3.00 \pm 0.92$, respectively), and percentage of the time with $\mathrm{pH}>7$ in the oesophagus $(12.13 \pm 27.42$ vs. $31.5 \pm 5.43$, respectively). The data are shown in Table II.

Table II. Average values $(\mathrm{M} \pm \mathrm{m})$ of 24-hour oesophageal impedance-pH-monitoring in different groups of patients

\begin{tabular}{|c|c|c|}
\hline $\begin{array}{l}\text { Indicators of } 24 \text {-hour } \\
\text { impedance-pH monitoring }\end{array}$ & $\begin{array}{l}\text { Patients with } \\
\geq 8 \text { points } \\
\text { according to } \\
\text { GerdQ }\end{array}$ & $\begin{array}{l}\text { Patients with } \\
<8 \text { points } \\
\text { according to } \\
\text { GerdQ }\end{array}$ \\
\hline Acid refluxes & $55.38 \pm 6.12^{*}$ & $23.29 \pm 6.53^{*}$ \\
\hline Weakly acid refluxes & $19.5 \pm 5.15$ & $23.50 \pm 3.02$ \\
\hline Weakly alkaline refluxes & $3.69 \pm 1.41$ & $3.93 \pm 1.4$ \\
\hline Gas refluxes & $1.46 \pm 0.43^{*}$ & $3.46 \pm 0.86^{\star}$ \\
\hline Liquid refluxes & $71.15 \pm 8.37^{*}$ & $33.8 \pm 5.97^{\star}$ \\
\hline Mixed refluxes (gas - liquid) & $13.15 \pm 3.73$ & $16.08 \pm 3.57$ \\
\hline Acid refluxes, lasting $>5 \mathrm{~min}$ & $3.46 \pm 0.80$ & $3.14 \pm 1.38$ \\
\hline Acid exposure time (AET) & $12.42 \pm 3.65^{*}$ & $3.00 \pm 0.92^{*}$ \\
\hline Time with $\mathrm{pH}>7$ & $12.13 \pm 5.60^{*}$ & $31.5 \pm 5.43^{*}$ \\
\hline
\end{tabular}


Table III. Relationship between the issues addressed by the GerdQ and the results of the 24-hour impedance-pH monitoring

\begin{tabular}{|c|c|c|c|c|c|c|}
\hline $\begin{array}{l}\text { Indicators of 24-hour } \\
\text { impedance-pH monitoring }\end{array}$ & Heartburn & Regurgitation & Epigastric pain & Nausea & $\begin{array}{l}\text { Nocturnal } \\
\text { episodes of } \\
\text { heartburn }\end{array}$ & $\begin{array}{c}\text { Taking } \\
\text { of additional } \\
\text { medication } \\
\text { for heartburn }\end{array}$ \\
\hline Acid refluxes & $0.659^{*}$ & $0.655^{*}$ & $0.556^{*}$ & $0.406^{\star}$ & $0.550^{*}$ & 0.110 \\
\hline Weakly acid refluxes & 0.143 & 0.140 & 0.076 & 0.201 & 0.021 & 0.158 \\
\hline Weakly alkaline refluxes & 0.087 & 0.189 & -0.192 & 0.166 & 0.148 & 0.077 \\
\hline Gas refluxes & -0.103 & -0.097 & 0.129 & -0.050 & 0.034 & -0.123 \\
\hline Liquid refluxes & $0.497^{*}$ & $0.663^{*}$ & $0.441^{*}$ & $0.405^{\star}$ & $0.481^{*}$ & 0.290 \\
\hline Mixed refluxes (gas - liquid) & 0.288 & 0.020 & 0.002 & 0.280 & 0.070 & 0.111 \\
\hline Acid refluxes, lasting $>5 \mathrm{~min}$ & 0.337 & 0.073 & 0.233 & $0.572^{\star}$ & 0.316 & -0.067 \\
\hline Acid exposure time (AET) & $0.742^{*}$ & $0.505^{*}$ & $0.566^{*}$ & $0.399^{*}$ & $0.508^{\star}$ & 0.145 \\
\hline Time with $\mathrm{pH}>7$ & -0.163 & -0.188 & -0.099 & -0.088 & 0.076 & -0.028 \\
\hline
\end{tabular}

${ }^{*} p<0.05$.

\section{Relationship between the different issues addressed by GerdQ and results of 24-hour impedance-pH monitoring}

We also sought to identify questions from the GerdQ questionnaire that would be sensitive to 24hour oesophageal impedance-pH monitoring results. For this purpose, the correlation coefficient between the patients' responses to each of the six questions on the GerdQ questionnaires and the 24-hour oesophageal-impedance $\mathrm{pH}$-monitoring results was determined. A statistically significant strong correlation was found between the AET and the incidence of heartburn $\left(r_{s}=0.74\right)$. Correlation of medium strength was found between acid refluxes and the incidence of heartburn $\left(r_{s}=0.66\right)$, regurgitation $\left(r_{s}=0.66\right)$, epigastric pain $\left(r_{s}=0.56\right)$, and nocturnal heartburn $\left(r_{s}=0.55\right)$; between the total number of fluid refluxes and the incidence of heartburn $\left(r_{s}=0.50\right)$, and regurgitation $\left(r_{s}=0.66\right)$; the number of prolonged acid refluxes ( $>5 \mathrm{~min}$ ) and the incidence of nausea $\left(r_{s}=\right.$ 0.57); and between the AET and the incidence of regurgitation $\left(r_{s}=0.51\right)$, epigastric pain $\left(r_{s}=0.57\right)$, and nocturnal episodes of heartburn $\left(r_{s}=0.51\right)$. A weak correlation was found between the number of acid refluxes and the incidence of nausea $\left(r_{s}=0.41\right)$; the total number of fluid refluxes and the incidence of epigastric pain $\left(r_{s}=0.44\right)$, nausea $\left(r_{s}=\right.$ $0.41)$, and nocturnal episodes of heartburn $\left(r_{s}=0.48\right)$; and between the AET and the incidence of nausea $\left(r_{s}=0.40\right)$. Other indicators did not show a statistically significant relationship (Table III).

\section{GerdQ Questionnaire sensitivity and specificity}

While using the GerdQ questionnaire, GERD was diagnosed (total score $\geq 8$ ) in 12 patients out of $28(42.9 \%)$. Subsequently, in 11 of them the diagnosis of GERD was confirmed with 24-hour oesophageal impedance-pH monitoring, and in 1 patient was excluded (Table IV). In 16 patients, GERD was not diagnosed (score $<8$ ). The percentage of patients with an overall score of $\geq 8$ among those who had instrument-confirmed GERD (11 out of 14) was $78.6 \%$ - this is the sensitivity of the questionnaire. The percentage of patients with a score of $<8$ (13) among those who had GERD excluded by the instrumental method (14) was $92.9 \%$ - this is the specificity of the GerdQ questionnaire. The accuracy of the questionnaire (diagnostic efficiency) was $85.7 \%$.

\section{Discussion}

The greater correlation for the GerdQ questionnaire suggests that this questionnaire is more sensitive to

Table IV. The accuracy of the GerdQ questionnaire compared to the results of the 24-hour oesophageal impedance-pH monitoring

\begin{tabular}{lcc} 
Scores of the GerdQ Questionnaire & $\begin{array}{c}\text { GERD } \\
\text { confirmed }\end{array}$ & $\begin{array}{c}\text { GERD } \\
\text { excluded }\end{array}$ \\
\hline Total scores $\geq 8$ & 11 & 1 \\
\hline Total scores $<8$ & 3 & 13
\end{tabular}


GERD compared to GSRS. The high level of correlation between the sum of GerdQ questionnaire scores and the key indicators of the 24-hour impedance-pH monitoring indicates that the questionnaire is sufficiently sensitive to the presence of pathological acidic and fluid refluxes, and also that it exceeds the time limit during which the $\mathrm{pH}$ in the oesophagus is < 4 (AET) and can be useful for routine diagnosis of GERD. Our results sug gest that the frequency of reflux symptoms (from the GerdQ questionnaire) is more correlated with abnormal reflux than with the intensity of GSRS reflux complaints. The correlation between individual issues addressed by the questionnaire and 24-hour oesophageal impedance-pH monitoring data has less strength than the total score of the GerdQ questionnaire, which indicates that the total questionnaire score is more informative when used for the purpose of diagnosing GERD.

The results of our study are similar to those found in the validations and baseline estimates of GerdQ in other populations. For example, in the initial study where the questionnaire was developed ( $n=308 \mathrm{sub}$ jects), a score $\geq 8$ showed a sensitivity and specificity of $64.6 \%$ and $71.4 \%$, respectively [17]. In a study by Lacy et al. [22], where the comparison of the questionnaire was conducted with 24-hour Bravo $\mathrm{pH}$ monitoring, sensitivity and specificity were indicated at $71 \%$ and $41 \%$, respectively. Such low rates are probably related to the fact that the study was conducted at the tertiary level, in which there is a large percentage of patients with refractory GERD, patients with atypical GERD, and patients with functional heartburn. The results of the study by Suzuki et al. indicate a sensitivity of the GerdQ questionnaire of $34.3 \%$ and specificity of $82.5 \%$ when comparing the results with those of upper endoscopy. In a study by Zavala-Gonzales et al. [25] comparisons of the results of the questionnaire with the results of endoscopy and/or $\mathrm{pH}$ monitoring of the oesophagus were performed, indicating the GerdQ sensitivity and specificity to be $71.6 \%$ and $72.2 \%$, respectively. The results of a multicentre study in Russia showed a sensitivity of $65.4 \%$ and a specificity of $91.7 \%$. In this study, upper endoscopy and $\mathrm{pH}$ monitoring were used as comparative methods [21]. The somewhat higher sensitivity and specificity of GerdQ in our study compared to similar studies is, in our opinion, a result of comparing the results of the questionnaire with impedance-pH monitoring of the oesophagus, which gives a more accurate assessment of pathological GER, and including a relatively small number of patients in the study.

Finally, it is important to note that, although GerdQ is a useful diagnostic tool, it should not be considered as a unique diagnostic test. It can, however, be used as a baseline test in the absence of alarm symptoms.
It can also be used to control the therapeutic effect of treatment of GERD, but in the absence of response to treatment it is necessary to confirm the diagnosis of GERD by impedance-pH monitoring and/or endoscopy, respectively.

\section{Conclusions}

The use of the GerdQ questionnaire for the diagnosis of GERD is optimal in everyday practice for deciding whether to prescribe ex juvantibus therapy, or whether to use instrumental examination methods (upper endoscopy, oesophageal $\mathrm{pH}$ monitoring, oesophageal impedance-pH monitoring) because it showed a significantly strong correlation between the total score of the questionnaire and the key indicators of 24-hour impedance-pH monitoring (AET, acid reflux episodes, fluid reflux episodes). Our results suggest that the frequency of reflux symptoms (from the GerdQ questionnaire) is bettter correlated with abnormal reflux than the intensity of GSRS reflux complaints.

The correlation between the evaluation of individual issues of GerdQ questionnaire and impedance-pH monitoring data was weaker than the total score, which indicates the advantage of using the total questionnaire score for diagnostic purposes in order to obtain the most reliable results.

As a result of this study, the GerdQ questionnaire showed a sensitivity of $78.6 \%$, specificity of $92.9 \%$, and accuracy (diagnostic efficiency) of $85.7 \%$. It should be noted that the patients who participated in the study were patients who had been referred to a secondary level of care.

\section{Conflict of interest}

The authors declare no conflict of interest.

\section{References}

1. Katz PO, Gerson LB, Vela MF. Guidelines for the diagnosis and management of gastroesophageal reflux disease. Am J Gastroenterol 2013; 108: 308-28.

2. De Vault KR, Castell DO. Updated guidelines for the diagnosis and treatment of gastroesophageal reflux disease. Am J Gastroenterol 2005; 100: 190-200.

3. Giannini EG, Zentilin P, Dulbecco P, et al. Management strategy for patients with gastroesophageal reflux disease: a comparison between empirical treatment with esomeprazole and endoscopy-oriented treatment. Am J Gastroenterol 2008; 103 : 267-75.

4. Inadomi JM, Jamal R, Murata GH, et al. Step-down management of gastroesophageal reflux disease. Gastroenterology 2001; 121: 1095-100.

5. Badillo R, Dawn F. Diagnosis and treatment of gastroesophageal reflux disease. World J Gastrointest Pharmacol Ther 2014; 5: 105-12. 
6. Silny J. Intraluminal multiple electric impedance procedure for measurement of gastrointestinal motility. J Gastrointest Moti 1991; 3: 151-62.

7. Sifrim D, Castell D, Dent J, et al. Gastro-oesophageal reflux monitoring: review and consensus report on detection and definitions of acid, non-acid, and gas reflux. Gut 2004; 53 : 1024-31.

8. Cho YK. How to interpret esophageal impedance $\mathrm{pH}$ monitoring. J Neurogastroenterol Motil 2010; 16: 327-30.

9. Vakil N, van Zanten SV, Kahrillas P, et al. The Montreal definition and classification of GERD: a global evidence-based consensus. Am J Gastroenterol 2006; 101: 1900-20.

10. Tytgat GN, Mccoll K, Tack J, et al. New algorithm for the treatment of gastro-esophageal reflux disease. Aliment Pharmacol Ther 2008; 27: 249-56.

11. Shaheen NJ, Hansen RA, Morgan DR, et al. The burden of gastrointestinal and liver diseases. Am J Gastroenterol 2006; 101: 2128-38.

12. Tutuian R, Castell DO. Management of gastroesophageal reflux disease. Am J Med Sci 2003; 326: 309-18.

13. Maev IV, Samsonov AA, Andreev NG. Simptom izzhogi: privyichnyiy diskomfort ili sereznaya problema? Farmateka 2011; 10: $18-25$

14. Pare P, Meyer F, Armstrong D, et al. Validation of the GSFQ, a self-administered symptom frequency questionnaire for patients with gastroesophageal reflux disease. Can J Gastroenterol 2003; 17: 307-12.

15. Gyawali CP, Kahrilas PJ, Savarino E, et al. Modern diagnosis of GERD: the Lyon Consensus. Gut 2018; 67: 1351-62.

16. Kulich KR, Madisch A, Pacini F, et al. Reliability and validity of the Gastrointestinal Symptom Rating Scale (GSRS) and Quality of Life in Reflux and Dyspepsia (QOLRAD) questionnaire in dyspepsia: a six-country study. Health Qual Life Outcomes 2008; 6: 12.

17. Dent J, Vakil N, Jones R, et al. Accuracy of the diagnosis of GORD by questionnaire, physicians and a trial of proton pump inhibitor treatment: the Diamond study. Gut 2010; 59: 714-21.

18. Jonasson C, Moum B, Bang C, et al. Randomised clinical trial: a comparison between a GerdQ-based algorithm and an endoscopy-based approach for the diagnosis and initial treatment of GERD. Aliment Pharmacol Ther 2012; 35: 1290-300.

19. Jones R, Junghard O, Dent J, et al. Development of the GerdQ, a tool for the diagnosis and management of gastro-oesophageal reflux disease in primary care. Aliment Pharmacol Ther 2009; 30: 1030-8.

20. Norder Grusell E, Mjörnheim AC, Finizia C, et al. The diagnostic value of GerdQ in subjects with atypical symptoms of gastro-esophageal reflux disease. Scand J Gastroenterol 2018; 53 : 1165-70.

21. Kaybyisheva VO, Kucheryavyiy YA, Truhmanov AS, et al. RezuItatyi mnogotsentrovogo nablyudatelnogo issledovaniya po primeneniyu mezhdunarodnogo oprosnika GerdQ dlya diagnostiki gastroezofagealnoy reflyuksnoy bolezni. RZhGGK 2013; 5:15-23.

22. Lacy BE, Chehade R, Crowell MD. A prospective study to compare a symptom-based reflux disease questionnaire to 48-h wireless $\mathrm{pH}$ monitoring for the identification of gastroesophageal reflux. Am J Gastroenterol 2011; 106: 1604-11.
23. Jonasson C, Wernersson B, Hoff DA, et al. Validation of the GerdQ questionnaire for the diagnosis of gastro-oesophageal reflux disease. Aliment. Pharmacol Ther 2013; 37: 564-72.

24. Suzuki H, Matsuzaki J, Okada S, et al. Validation of the GerdQ questionnaire for the management of gastro-esophageal reflux disease in Japan. United Eur Gastroenterol J 2013; 1: 175-83.

25. Zavala-Gonzales MA, Azamar-Jacome AA, Meixueiro-Daza A, et al. Validation and diagnostic usefulness of gastroesophageal reflux disease questionnaire in a primary care level in Mexico. J Neurogastroenterol Motil 2014; 20: 475-82.

26. Bai Y, Du Y, Zou D, et al. Gastroesophageal Reflux Disease Questionnaire (GerdQ) in real-world practice: a national multicenter survey on 8,065 patients. J Gastroenterol Hepatol 2013; 28: 626-31.

27. Teruel-Sánchez-Vegazo C, Faro-Leal V, Muriel-García A, et al. Sensitivity and specificity of the Gastrointestinal Short Form Questionnaire in diagnosis of gastroesophageal reflux disease. Rev Esp Enferm Dig 2016; 108: 174-80.

Received: 12.09.2019

Accepted: 26.11.2019 